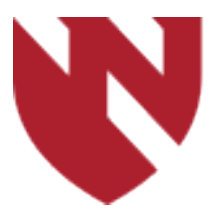

October 2021

\title{
Postoperative Outcomes of Hip Fracture Surgery in Geriatric Patients on Clopidogrel or Warfarin at the Time of Surgery
}

Josh Locker

Univeristy of Nebraska Medical Center

Elizabeth Lyden

University of Nebraksa Medical Center

Justin Siebler

University of Nebraska Medical Center

Tell us how you used this information in this short survey.

Follow this and additional works at: https://digitalcommons.unmc.edu/gmerj

Part of the Higher Education Commons, Internal Medicine Commons, and the Orthopedics Commons

\section{Recommended Citation}

Locker, J., Lyden, E., , Siebler, J. Postoperative Outcomes of Hip Fracture Surgery in Geriatric Patients on Clopidogrel or Warfarin at the Time of Surgery. Graduate Medical Education Research Journal. 2021 Oct 04; 3(1).

https://digitalcommons.unmc.edu/gmerj/vol3/iss1/2

This Original Report is brought to you for free and open access by DigitalCommons@UNMC. It has been accepted for inclusion in Graduate Medical Education Research Journal by an authorized editor of DigitalCommons@UNMC. For more information, please contact digitalcommons@unmc.edu. 


\title{
Postoperative Outcomes of Hip Fracture Surgery in Geriatric Patients on Clopidogrel or Warfarin at the Time of Surgery
}

\author{
Abstract \\ BACKGROUND: The purpose of our study is to evaluate if surgical intervention in the setting of an \\ elevated INR or continued use of clopidogrel lead to elevated post-operative mortality and/or morbidity \\ compared to INR reversal or surgical delay. \\ METHODS: We retrospectively reviewed 1,007 patients age $>55$ undergoing hip fracture fixation at our \\ institution over a 10 year span. We placed patients into four groups based upon their anticoagulation \\ status at the time of surgery. Descriptive statistics were utilized to evaluate for differences in mortality \\ rates, blood loss, time to surgery, and wound complications.
}

RESULTS: Comorbid conditions occurred at a higher rate in patients on an anticoagulant. There was found to be no difference ( $p>05$ ) between all four groups in regards to units of blood transfused, net preoperative to post-operative hemoglobin change, 30 day mortality, wound infections, and post-operative thromboembolic events. Average time to surgery was less than two days for all groups.

CONCLUSION: There was no statistically significant increase in local or systemic complications in patients who underwent surgery in the setting of an INR $>1.5$ or continued use of clopidogrel. Our study supports the finding that appropriate and attentive management of anticoagulants from the time of admission can minimize surgical delays and result in time to surgery in less than two days for patients with an elevated INR at the time of presentation with no effect on mortality or morbidity.

\section{Keywords}

hip fracture, geriatric, clopidogrel, warfarin, surgical timing

\section{Creative Commons License}

\section{(c) $(1)(9)$}

This work is licensed under a Creative Commons Attribution-Noncommercial-No Derivative Works 4.0 License. 


\section{Postoperative Outcomes of Hip Fracture Surgery in Geriatric Patients on Clopidogrel or Warfarin at the Time of Surgery}

Josh Locker ${ }^{1}$, Elizabeth Lyden², Justin Siebler ${ }^{1}$

${ }^{1}$ University of Nebraska Medical Center, College of Medicine, Department of Orthopaedic Surgery and Rehabilitation

${ }^{2}$ University of Nebraska Medical Center, College of Public Health, Department of Biostatistics

https://doi.org/10.32873/unmc.dc.gmerj.3.1.003

\begin{abstract}
Background: The purpose of our study is to evaluate if surgical intervention in the setting of an elevated INR or continued use of clopidogrel leads to elevated post-operative mortality and/or morbidity compared to INR reversal or surgical delay.
\end{abstract}

Methods: We retrospectively reviewed 1,007 patients age $>55$ years of age that underwent hip fracture fixation at our institution over a 10 -year period. We placed patients into four groups based upon their anticoagulation status at the time of surgery. Descriptive statistics were utilized to evaluate for differences in mortality rates, blood loss, time to surgery, and wound complications.

Results: The presence of comorbid conditions was noted to be higher in patients on an anticoagulant. We found no difference ( $p>.05)$ between all four groups with regards to units of blood transfused, net preoperative to post-operative hemoglobin change, 30-day mortality, wound infections, and post-operative thromboembolic events. The average time to surgery was less than two days for all groups.

Conclusion: There was no statistically significant increase in local or systemic complications in patients who underwent surgery in the setting of an INR $>1.5$ or continued use of clopidogrel. Our study supports the finding that appropriate and attentive management of anticoagulants from the time of admission can minimize surgical delays and result in time to surgery of less than two days for patients with an elevated INR at the time of presentation with no adverse effect on mortality or morbidity.

\section{Introduction}

Hip fractures are a common injury in the elderly population and are associated with a high level of morbidity and mortality. In the U.S., roughly 280,000 hip fractures occur annually, and this number may surpass 500,000 by the year $2040 .{ }^{1}$ One-year mortality rates of $26 \%$ to $33 \%$ have been reported. ${ }^{2,3,4}$ Many patients require an increased level of care 1 year after hip fracture. ${ }^{5,6}$

Multiple studies have demonstrated the importance of early surgical intervention in reducing the morbidity and mortality associated with these fractures. ${ }^{1,7,8}$ It has been demonstrated that patients on Coumadin often experience delays in surgical treatment secondary to an elevated INR. ${ }^{9}{ }^{10}$ Instituting a warfarin management protocol, which allows for early administration of Vitamin K has been shown to diminish time to surgery in this patient population. ${ }^{9,10}$ However it is currently not known what INR value represents a safe cut-off to initiate surgical treatment. ${ }^{10}$ In addition, while an increased INR theoretically would increase the rate of complications such as intraoperative blood loss, there is minimal literature demonstrating that such complications occur and that reversal is necessary.

The available treatment options for hip fractures have varying degrees of invasiveness and associated blood loss. It is unclear if the reversal of Coumadin prior to surgery is necessary for some or all of these surgical interventions, however it is clear that this process can lead to delays in surgery. ${ }^{12,13}$

The purpose of our study was to evaluate if surgery in the setting of an elevated INR resulted in increased morbidity and mortality. We also assessed the time to surgery to determine if there was a surgical delay in those on Coumadin compared to those not on anticoagulants. Our hypothesis was that there would be no difference between the groups in terms of blood loss or post-operative mortality and morbidity.

\section{Materials and Methods}

We retrospectively reviewed 1,007 patients age $>55$ years of age that underwent hip fracture fixation at our institution over a 12-year period from 1/1/2004-1/1/2016. Those who were on the newer anticoagulant regimens were excluded. Hip fractures were defined as a fracture of the femoral neck, intertrochanteric fractures, or subtrochanteric fractures. Periprosthetic fractures, surgical treatment for non-unions or malunions were excluded, as were patients who were less than 55 or with fractures distal to the subtrochanteric region. Surgical interventions included percutaneous pinning, cephalomedullary nail fixation, dynamic hip screw fixation, hemiarthroplasty for fracture and total hip arthroplasty for fracture.
We placed patients into four groups based upon their status at the time of surgery: 1) patients not on Coumadin or clopidogrel; 2) patients only on clopidogrel; 3) patients on Coumadin upon presentation with INR $<1.5$ at the time of surgery; 4) patients on Coumadin upon presentation with INR $>1.5$ at the time of surgery. Descriptive statistics were utilized to evaluate for differences in estimated blood loss, changes in hemoglobin, transfusion rates, mortality rates, time to surgery and wound complications. Comparisons were also made regarding associated medical co-morbidities. Descriptive statistics (counts and percentages, means, standard deviations, medians, minimums and maximums) were used to summarize the data. Fisher's exact test was used to look at associations of categorical variables. Analysis of variance (ANOVA) was used to compare continuous data between the four patient groups. If the overall p-value from the ANOVA model was statistically significant, pairwise comparisons were adjusted using Tukey's test. A p-value $<0.05$ was considered statistically significant.

\section{Results}

Of the 1007 patients included in the study, $832,52,111$ and 12 patients were divided into Groups 1, 2, 3 and 4 respectively (Table 1). Comorbid conditions including congestive heart failure, coronary artery disease, chronic kidney disease, and diabetes occurred at a higher rate in patients on either anticoagulant

Table 1.

Frequency and percentage of total patients studied (N=1007) and their classification into 4 groups.

\begin{tabular}{llll}
$\begin{array}{l}\text { Patient } \\
\text { Group }\end{array}$ & Frequency & $\%$ & $\begin{array}{l}\text { Cumulative } \\
\text { Frequency }\end{array}$ \\
\hline $\begin{array}{l}\text { No } \\
\text { coumadin/ } \\
\text { warfarin } \\
\text { (Group \#1) }\end{array}$ & 832 & 82.62 & 832 \\
\hline $\begin{array}{l}\text { Clopdiogrel } \\
\text { (Group \#2) }\end{array}$ & 52 & & \\
\hline $\begin{array}{l}\text { Coumadin, } \\
\text { INR <1.5/K/ }\end{array}$ & & 5.111 & 884 \\
FFP (Group & & 11.02 & 995 \\
\#3) & & \\
\hline $\begin{array}{l}\text { Coumadin, } \\
\text { INR }>1.5\end{array}$ & & & \\
(Group \#4) & & 1.19 & 1007 \\
\hline
\end{tabular}


when compared to patients not on anticoagulants $(\mathrm{p}<.0001 ; \mathrm{p}<.0001 ; \mathrm{p}=.0035$; $\mathrm{p}=.008$ respectively). We found no difference $(\mathrm{p}>.05)$ between all four groups with regards to units of blood transfused $(\mathrm{p}=-0.15)$, net preoperative to post-operative hemoglobin change $(p=0.44), 30$ day mortality $(p=0.0689)$, wound infections $(\mathrm{p}=0.6851)$, and postoperative thromboembolic events $(\mathrm{p}=0.1429)$ (Table 2). In addition, there was no statistically significant difference between the groups with regards to age $(p=.52)$, BMI $(p=0.20)$, preoperative hgb $(p=0.57)$, post-operative hgb nadir $(\mathrm{p}=0.85)$, and units transfused $(\mathrm{p}=0.15)$. There was a statistically significant difference in estimated intraoperative blood loss between groups 1 and 3 $(\mathrm{p}=.0079)$. Average time to surgery was 1.6 days for group 1, 1.9 days for group 2, 1.95 days for group 3 , and 1.42 days in group four $(p=0.14)$. We obtained IRB approval for this study.

\section{Discussion}

Multiple studies have demonstrated that early surgical intervention in the setting of geriatric hip fractures can result in improved outcomes. ${ }^{1,2,3}$ Previous research has shown that patients who present with an elevated INR are at an increased risk for surgical delay which could potentially place them at risk for poorer outcomes. ${ }^{4}$ However to date it is unclear if these delays are necessary

\section{Table 2.}

Demographics and variables evaluated amongst the four groups studied showing the Mean with Standard deviation, Median, Minimum, and Maximum. All values showed a $p>0.5$ with the exception of comparing Group \#1 and Group \#3 estimated intra-operative blood loss ( $p=.0079$ ).

\begin{tabular}{|c|c|c|c|c|c|c|c|}
\hline Patient Groups & Variable & Mean & Std Dev & Median & Min. & Max. & $\mathbf{N}$ \\
\hline $\begin{array}{l}\text { No coumadin/warfarin } \\
\text { (Group \#1) }\end{array}$ & $\begin{array}{l}\text { age } \\
\text { bmi } \\
\text { time to surgery (days) } \\
\text { Estimated blood loss } \\
\text { pre-operative hgb } \\
\text { postoperative hgb nadir } \\
\text { units transfused }\end{array}$ & $\begin{array}{l}79.44 \\
24.70 \\
1.60 \\
195.29 \\
11.81 \\
8.97 \\
1.13\end{array}$ & $\begin{array}{l}10.48 \\
5.94 \\
1.60 \\
210.36 \\
4.87 \\
1.51 \\
1.31\end{array}$ & $\begin{array}{l}81.00 \\
23.70 \\
1.00 \\
150.00 \\
11.60 \\
8.70 \\
1.00\end{array}$ & $\begin{array}{l}49.00 \\
14.20 \\
0.00 \\
0.00 \\
7.20 \\
5.30 \\
0.00\end{array}$ & $\begin{array}{l}105.00 \\
56.00 \\
19.00 \\
2500.00 \\
142.00 \\
14.60 \\
10.00\end{array}$ & 832 \\
\hline $\begin{array}{l}\text { Clopdiogrel } \\
\text { (Group \#2) }\end{array}$ & $\begin{array}{l}\text { age } \\
\text { bmi } \\
\text { time to surgery (days) } \\
\text { Estimated blood loss } \\
\text { pre-operative hgb } \\
\text { postoperative hgb nadir } \\
\text { units transfused }\end{array}$ & $\begin{array}{l}81.23 \\
24.14 \\
1.90 \\
215.24 \\
11.37 \\
8.91 \\
1.33\end{array}$ & $\begin{array}{l}9.90 \\
3.62 \\
3.12 \\
149.78 \\
1.79 \\
1.62 \\
1.35\end{array}$ & $\begin{array}{l}82.00 \\
24.00 \\
1.00 \\
200.00 \\
11.40 \\
8.75 \\
1.00\end{array}$ & $\begin{array}{l}58.00 \\
18.60 \\
0.00 \\
50.00 \\
7.30 \\
5.40 \\
0.00\end{array}$ & $\begin{array}{l}101.00 \\
32.90 \\
23.00 \\
700.00 \\
16.30 \\
13.80 \\
4.00\end{array}$ & 52 \\
\hline $\begin{array}{l}\text { Coumadin, } \\
\text { INR < } 1.5 / \mathrm{K} / \mathrm{FFP} \\
\text { (Group \#3) }\end{array}$ & $\begin{array}{l}\text { age } \\
\text { bmi } \\
\text { time to surgery (days) } \\
\text { Estimated blood loss } \\
\text { pre-operative hgb } \\
\text { postoperative hgb nadir } \\
\text { units transfused }\end{array}$ & $\begin{array}{l}80.24 \\
26.20 \\
1.95 \\
275.17 \\
11.22 \\
9.09 \\
1.44\end{array}$ & $\begin{array}{l}9.76 \\
5.76 \\
1.74 \\
247.14 \\
2.01 \\
1.69 \\
1.47\end{array}$ & $\begin{array}{l}83.00 \\
25.00 \\
2.00 \\
200.00 \\
10.90 \\
8.80 \\
2.00\end{array}$ & $\begin{array}{l}46.00 \\
15.00 \\
0.00 \\
50.00 \\
6.80 \\
6.30 \\
0.00\end{array}$ & $\begin{array}{l}98.00 \\
45.00 \\
12.00 \\
1600.00 \\
18.00 \\
15.40 \\
7.00\end{array}$ & 111 \\
\hline $\begin{array}{l}\text { Coumadin, } \\
\text { INR >1.5 (Group \#4) }\end{array}$ & $\begin{array}{l}\text { age } \\
\text { bmi } \\
\text { time to surgery (days) } \\
\text { Estimated blood loss } \\
\text { pre-operative hgb } \\
\text { postoperative hgb nadir } \\
\text { units transfused }\end{array}$ & $\begin{array}{l}77.73 \\
27.03 \\
1.42 \\
227.78 \\
11.64 \\
8.93 \\
0.80\end{array}$ & $\begin{array}{l}8.09 \\
6.43 \\
1.56 \\
203.27 \\
1.57 \\
1.20 \\
1.40\end{array}$ & $\begin{array}{l}75.00 \\
30.00 \\
1.00 \\
150.00 \\
11.35 \\
8.75 \\
0.00\end{array}$ & $\begin{array}{l}69.00 \\
18.51 \\
0.00 \\
50.00 \\
9.70 \\
6.60 \\
0.00\end{array}$ & $\begin{array}{l}92.00 \\
33.90 \\
5.00 \\
700.00 \\
14.70 \\
10.90 \\
4.00\end{array}$ & 12 \\
\hline
\end{tabular}
co-morbidities including congestive heart patients at the time of admission can minimize surgical delays in treatment.

elevated INR is associated with an increase in adverse outcomes. Our study found a significant association with anticoagulant use and presence of other peri-operative failure, coronary artery disease, chronic kidney disease, and diabetes. This suggests that even with optimal management of their anticoagulation these patients may be at increased risk for complications due to these associated medical co-morbidities.

In spite of this, no significant increase in postoperative blood loss, wound complications, post-operative thrombo-embolic incidences was noted. While not statistically significant, there was a trend towards increasing mortality rates in patients on Coumadin. This may be related to the significantly higher rates of medical co-morbidities noted within these groups. In addition, our study did not show a statistically significant difference in time to surgery in patients on anticoagulants compared to those not on any anticoagulant (1.6 days for group one, 1.9 days for group two, 1.95 days for group three, and 1.42 days in group four $(\mathrm{p}=0.14))$. The mean time to surgery for those patients on Coumadin who did not undergo surgery until they achieved an INR of less than 1.5 was under two days. This finding is consistent with other recent studies which show that careful management of these

In summary, in this study we did not find any statistically significant increase in local or systemic complications in patients who underwent surgery in the setting of an INR $>1.5$. However due to the small sample size in group four (12 patients) we are unable to prove or disprove our null hypothesis. Our study does support the finding that appropriate and attentive management of anticoagulants from the time of admission can minimize surgical delays and result in time to surgery of less than two days for patients with an elevated INR at the time of presentation.

\section{References}

1 Bhandari M, Devereaux PJ, Tornetta P III, Swiontkowski MF, Berry DJ, Haidukewych G, et al. Operative management of displaced femoral neck fractures in elderly patients. An international survey. $J$ Bone Joint Surg Am. 2005;87:2122-30.

2 Aharonoff GB, Koval KJ, Skovron ML, Zuckerman JD. Hip fractures in the elderly: predictors of one year mortality. J Orthop Trauma. 1997 Apr; 11(3):162-5.

3 Bentler SE, Liu L, Obrizan M, et al. The aftermath of hip fracture: discharge placement, functional status change, and mortality. Am J Epidemiol. 2009;170(10):1290-1299

4 Roche JJ, Wenn RT, Sahota O, Moran CG. Effect of comorbidities and postoperative complications on mortality after hip fracture in elderly people: prospective observational cohort study. $B M J$. 2005;331(7529):1374

5 Holt G, Smith R, Duncan K, Hutchison JD, Gregori A. Outcome after surgery for the treatment of hip fracture in the extremely elderly. J Bone Joint Surg Am. 2008;90(9):1899-1905

6 Braithwaite RS, Col NF, Wong JB. Estimating hip fracture morbidity, mortality and costs. J Am Geriatr Soc. 2003;51(3):364-370

7 Carretta E, Bochicchio V, Rucci P, Fabbri G, Laus M, Pia Fantini M. Hip Fracture: Effectiveness of Early Surgery to Prevent 30-dayMortality. International Orthopaedics (SICOT) International Orthopaedics 35.3 (2010):419-24. Web.

8 Bottle A, Aylin P. Mortality Associated with Delay in Operation after HipFracture: Observational Study. BMJ 332.7547 (2006): 947-51. Web.

9 Al-Rashid, Mamun, and Martyn J. Parker. Anticoagulation Management in Hip FracturePatients on Warfarin."Injury36.11 (2005): 1311-315. Web.

10 Bansal R, Watson DK. Surgical delay in acute admissions on warfarin: are we doing enough? International Journal of Clinical Practice. 2005;59(11):1283-1288.

11 Charalambous CP, Yarwood S, Paschalides C, Siddique I, Hirst P, Paul A. Factors Delaying Surgical Treatment of Hip Fractures in Elderly Patients. Annals of The Royal College of Surgeons of England 85.2 (2003): 117-19. Web.

12 Ashouri F, Al-Jundi W, Patel A, Mangwani J. Management of warfarin anticoagulation in patients with fractured neck of femur. ISRN Hematol. 2011;2011:294628. doi:10.5402/2011/294628

13 Bhatia M, Talawadekar G, Parihar S, Smith A. An Audit of the Role of Vitamin K in the Reversal of International Normalised Ratio (INR) in Patients Undergoing Surgery for Hip Fracture. The Annals of The Royal College of Surgeons of England Annals 92.6 (2010): 473-76. Web. 